\title{
UMA SEGUNDA ESTRANGEIRA: MEMÓRIAS DE LADY CALLCOTT (MARIA GRAHAM) SOBRE DOM PEDRO I
}

\author{
Júlia Braga Neves ${ }^{1^{*}}$ \\ ${ }^{1}$ Universidade Federal do Rio de Janeiro, Rio de Janeiro, RJ, Brasil
}

\begin{abstract}
Resumo:
Este $\operatorname{artigo}^{1}$ tenciona analisar o manuscrito não finalizado de Lady Maria Callcott, intitulado Escorço biográfico de Dom Pedro I e a exposição da violência sofrida por Maria Leopoldina no palácio. Comparando o manuscrito com o Journal of a Voyage to Brazil, publicado pela mesma autora em 1824, argumenta-se que o diário de 1824 representa Dom Pedro como um político e estadista, enquanto seu esboço biográfico, publicado postumamente, revela a crueldade, possessividade e perversidade de Dom Pedro a partir da descrição minuciosa de seu casamento com dona Leopoldina, que se tornou amiga de Callcott. Disputando o argumento da biógrafa de Callcott, Regina Akel, de que o retrato construído pela viajante seria uma forma de autopromoção e, comparando o relato de 1834-1835 com as respectivas biografias sobre Dom Pedro I e Maria Leopoldina, conclui-se que o manuscrito sobre o imperador é um documento histórico que denuncia os maus tratos vivenciados pela austríaca.

Palavras-chave: Maria Graham; Lady Callcott; Imperatriz Leopoldina; Dom Pedro I; literatura de viagem
\end{abstract}

\section{A SECOND FOREIGNER: MEMORIES OF LADY CALLCOTT (MARIA GRAHAM) ABOUT DOM PEDRO I}

\begin{abstract}
:
This article aims to analyze Lady Maria Callcott's unfinished manuscript intitled Life of Dom Pedro and its representation of the violence suffered by Empress Maria Leopoldina in the palace. By comparing Journal of a Voyage to Brazil, published in 1824 by the same author, I argue that the Graham's travel narrative in 1824 represents Dom Pedro as a politician and statist, while her unfinished manuscript, posthumously published, reveals the emperor's cruelty, possessiveness and perversity through her description of his marriage with empress Leopoldina, who became a close friend of Lady Callcott's. Disputing Regina Akel's argument, in which she contends that the traveler's memoir of Dom Pedro is a means of self-promotion, and comparing the 1834-1835 narrative to biographies of Dom
\end{abstract}

\footnotetext{
${ }^{*}$ Professora de Literatura em Língua Inglesa no Departamento de Letras Anglo-Germânicas da Universidade Federal do Rio de Janeiro. Doutora em Literatura e Cultura Inglesas pela Universidade Humboldt de Berlim e pelo King’s College London. E-mail: juliabneves@letras.ufrj.br. ORCID: https://orcid.org/0000-0003-4548-3491.
} 
Pedro I and Maria Leopoldina, I conclude that Callcott's manuscript is a historical document that denounces the emperor's ill treatment of his Austrian wife.

Key words: Maria Graham; Lady Callcott; Empress Leopoldina; Don Pedro I; travel literature 


\section{Introdução}

Entre setembro de 1834 e julho de 1835, Lady Maria Callcott, antes conhecida como Maria Graham, já apresentava sua saúde debilitada devido ao avanço de uma tuberculose que, desde 1831, a deixara tão extenuada que "nunca mais poderia aquela figura ativa e galante juntar-se ao mundo de homens e mulheres para conversas instigantes e a troca de ideias, fora das quatro paredes de sua própria casa" (GOTCH, 1937, p. 283, minha tradução²). Havia meses nos quais a viajante e escritora, bastante conhecida por seus relatos de viagem, mal conseguia segurar uma caneta. Foi durante um desses períodos que Lady Callcott ditou alguns escritos para que sua amiga íntima Caroline Fox, filantropista e reformadora social, os redigisse. Entre eles, a escritora narrara Escorço Biográfico de Dom Pedro I com uma notícia do Brasil e do Rio de Janeiro em seu tempo (Life of Don Pedro), manuscrito adquirido pela Biblioteca Nacional do Rio de Janeiro somente em 1938 e traduzido pelo professor e diretor da Casa Rui Barbosa à época, Américo Jacobina Lacombe. Em inglês, somente uma versão muito resumida do documento transcrito foi publicada como anexo na edição de Journal of a Voyage to Brazil (2010), editada por Jennifer Hayward e Maria Soledad Caballero ${ }^{3}$.

A decisão de recontar a vida de Dom Pedro I surgira logo após a morte do Imperador em 24 de setembro de 1824. Quando o conheceu, Lady Callcott ainda usava o sobrenome de seu primeiro marido, o capitão da Marinha Britânica Thomas Graham, que faleceu em 1822 durante a travessia entre o Brasil e o Chile. Foram as estadas nesses dois países que abriram os caminhos para que a viajante Maria Graham ${ }^{4}$ consolidasse o seu prestígio como autora de literatura de viagem, tendo publicado Journal of a Voyage to Brazil e Journal of a Residence in Chile, lançados em 1824 pela renomada editora John Murray, que, além de publicar escritores notórios como Jane Austen, Lord Byron e Walter Scott, era uma das principais editoras de literatura de viagem entre o final do século XVIII e ao longo do século XIX. Maria Graham destacava-se como principal autora desse gênero literário na editora (KEIGHREN; WITHERS; BELL, 2015, p. 25) e, embora a recepção de seus diários sobre a América do Sul nem sempre tenha sido positiva, a viajante é considerada uma importante fonte histórica sobre a independência do Brasil e sobre os primeiros anos do império de Dom Pedro I (COSTA, 2010, p. 7).

Graham chegou ao Brasil em setembro de 1821 e acompanhou de perto os eventos que levariam o Brasil à sua independência. A inglesa mantinha-se a par dos acontecimentos políticos não somente por sua atividade intelectual de estudos sobre a história e a cultura do Brasil, mas também em seu meio social: ela circulava pelas elites políticas brasileiras, tendo feito amizade com a família do então governador da província de Pernambuco, general Luís do Rego; era amiga do mercenário inglês lorde Cochrane, que teve papel crucial na independência do Chile e, mais tarde, na pacificação das províncias do norte brasileiro após a emancipação política do país de Portugal. Sobretudo, Graham construiu uma amizade inestimável com a imperatriz Leopoldina com quem se correspondeu até a morte da austríaca, em dezembro de 1826. 
Apesar de afirmar, em nota que precede o seu escrito sobre a vida de Dom Pedro I, que "tudo que se refere [a ela], pessoalmente, será naturalmente posto de lado" a fim de "esclarecer, não somente o [...] caráter [do imperador], mas o estado social do Brasil no seu tempo" (CALLCOTT, 1997, p. 63), é a amizade entre Lady Callcott e Maria Leopoldina que sobressai na narrativa. Em setembro de 1824, ela se instalou no Palácio Imperial para iniciar suas atividades como preceptora da princesa Maria da Glória, cargo que ocupou por menos de um mês devido a intrigas com as damas portuguesas e alguns criados no Paço que a chamavam de "uma segunda estrangeira [...] como se nenhuma dama portuguesa fosse competente para instruir as princesas" (CALLCOTT, 1997, p. 93, grifo no original). A primeira forasteira seria a própria dona Leopoldina, pois, segundo Callcott, as damas palacianas "haviam sempre lamentado a política que havia casado o jovem da Casa de Bragança com uma estrangeira, em vez de uma tia ou prima, como havia sido o costume invariável nas casas reais de Espanha e Portugal" (CALLCOTT, 1997, p. 93).

Para Regina Akel, um dos motivos que teriam levado a inglesa a escrever esse manuscrito sobre Pedro I seria revelar, dez anos depois, o porquê de sua expulsão repentina do Paço de São Cristóvão, tomando "a liberdade de entregar sua própria versão do sucesso, já que tanto a imperatriz quanto o imperador haviam falecido" (AKEL, 2011, p. 196, minha tradução ${ }^{5}$ ). De fato, o que impulsiona a escrita dessas memórias é a morte de Dom Pedro, conforme a própria Callcott admite em nota prévia. Porém, a exposição das intimidades e conflitos palacianos pode ser compreendida além de uma autopromoção da viajante para "manter sua importância como protagonista" (AKEL, 2011, p. 196, minha tradução ${ }^{6}$ ), como fizera em seus diários sobre o Brasil e o Chile. Embora o protagonismo de Callcott nesse relato seja indiscutível, argumento que seu papel de personagem principal e narradora seja construído a fim de denunciar os maus tratos sofridos por Dona Leopoldina no Palácio Imperial. Tendo sido confidente da imperatriz e testemunhado os desgostos dos últimos anos de sua vida e o declínio de sua saúde por conta de seu casamento com o português, é possível que a morte de Dom Pedro tenha trazido de volta os ressentimentos guardados não somente por sua demissão do cargo de preceptora, mas também pelos danos causados a Maria Leopoldina. É importante ressaltar que não se sabe se Callcott tinha realmente o intuito de publicar o Escorço biográfico, ainda que ela afirme que sua memória sobre o imperador possa "ser um dia examinada por alguém que esteja escrevendo a vida de Dom Pedro I" (CALLCOTT, 1997, p. 63), como efetivamente ocorreu. O manuscrito também é documento relevante para as biografias de Leopoldina, de Dom Pedro I e de sua amante, Domitila de Castro, conforme os respectivos livros de Paulo Rezzutti $(2017 ; 2015 ; 2013)$ sobre essas figuras históricas.

Mais que a produção de "sua própria versão do sucesso", como alega Akel, a inglesa relata os sofrimentos de Leopoldina e o caráter passional e possessivo de Dom Pedro. Segundo Callcott, o imperador era "sujeito a explosões repentinas de paixão violenta, logo sucedidas por uma generosa e franca delicadeza" (CALLCOTT, 1997, p. 103) e era rodeado de "maus conselheiros [...] [e] aduladores 
profissionais que, valendo-se de suas paixões, esperavam governá-lo, senão ao próprio Estado" (CALLCOTT, 1997, p. 107). Além disso, a viajante comenta - e muitas vezes critica - a educação das princesas, a situação política do Brasil e narra sua vida como educadora no Paço de São Cristóvão e, após esse período, quando voltou a viver no Rio de Janeiro durante quase um ano.

Este artigo tem o objetivo de analisar as maneiras pelas quais Lady Callcott esboça um retrato de Dom Pedro a partir da narração de seu violento relacionamento com sua esposa, expondo os abusos sofridos pela imperatriz no final de sua vida. A escritora avalia que "o que se refere [a Leopoldina] é a parte mais interessante da narrativa" (CALLCOTT, 1997, p. 62). Esta observação é pertinente, pois são os relatos sobre a vida da imperatriz no Palácio Imperial, que já eram conhecidos como rumores e haviam manchado a reputação do imperador na Europa ao longo da década de 1820, que demonstram um lado cruel de Pedro I em contraste com o caráter comunicativo e divertido de um homem que gostava do contato com o povo e que se tornou "um personagem das ruas, das praças, que se misturava com a gente comum, que não atendia às convenções, nunca permitindo que o príncipe sufocasse nele o homem" (LUSTOSA, 2006, p. 60).

Como demonstrarei, essa face descontraída de Dom Pedro fica menos evidente no Escorço biográfico de Lady Callcott justamente porque ela traz à tona as fraquezas e perversidades do imperador em relação à imperatriz. A própria expulsão de Graham do paço pode ser entendida como uma forma de isolar ainda mais Maria Leopoldina, que a esta altura já não contava com a companhia de "damas de sua nacionalidade em torno dela", mas somente "servidoras portuguesas, que não falavam senão a própria língua, e cuja educação se resumia nas regras de etiqueta da corte" (CALLCOTT, 1997, p. 93). Dona Leopoldina era culta e nutria interesse por botânica e mineralogia, enquanto seu marido e seu cunhado Dom Miguel foram descritos como "representantes genuínos e completos de uma nobreza caracteristicamente nacional, inculta, iletrada, toureira, fadista, dissipada, arruaceira" (LUSTOSA, 2006, p. 62). O casamento fora considerado uma inteligente jogada no âmbito da política internacional, pois a aliança matrimonial entre os príncipes "confundiam os interesses das dinastias de Habsburgo e Bragança no intuito de consolidar a monarquia instalada no Novo Mundo e fortalecer o sistema monárquico na Europa" (LUSTOSA, 2006, p. 77). A Casa de Habsburgo tradicionalmente optava pela conquista de territórios a partir de casamentos, e suas princesas eram criadas para cumprirem suas funções políticas. Por isso, obtinham um alto grau de ensino em inúmeros assuntos, como história, geografia, línguas estrangeiras, literatura, pintura, música, mineralogia e botânica (REZZUTTI, 2017, p. 759-760). Em suma, como todas as princesas da dinastia de Habsburgo, Leopoldina tinha "instrução suficiente para ser uma estadista” (REZZUTTI, 2017, p. 233).

Ao contrário de Dom Pedro, que obteve parca educação formal e era conhecido pela vulgaridade e falta de modos, a companhia de Maria Leopoldina contribuiria "para melhorar as maneiras e cultura geral do príncipe" (LUSTOSA, 2006, p. 87). De fato, isso ocorreria em termos de instrução intelectual, pois Leopoldina o instigara a melhorar a sua formação em música, teoria política e de 
estado, que teriam colaborado para que Dom Pedro "[começasse] a flertar com o liberalismo e com a ideia das liberdades individuais espalhadas por Napoleão na Europa" (REZZUTTI, 2017, p. 3753). No palácio, a combinação de um alto grau de instrução da imperatriz com a frequente conduta chula do imperador seria um desafio para Graham como preceptora, cujo objetivo era "salvar esta linda criança [a princesa Maria da Glória] das mãos das criaturas que a cercam, educá-la como uma dama européia [sic] - ensinar-lhe, já que ela terá de governar este grande país, que o Povo é menos feito para os Reis, que os Reis para o Povo" (CALLCOTT, 1997, p. 78).

A inglesa ficara assustada com o cotidiano e com os modos de Maria da Glória, cujo temperamento era comparável ao de seu pai (CALLCOTT, 1997, p. 89). A contratação de Graham para o cargo seria, inclusive, uma maneira de oferecer à princesa um grau de instrução semelhante ao de sua mãe, que estava aflita, como escrevera em carta à sua irmã Maria Luísa, porque "não [queriam lhe] conceder nem os direitos de uma mãe de decidir sobre a educação das [suas] filhas" (IMPERATRIZ LEOPOLDINA apud REZZUTTI, 2017, p. 5930). Na mesma carta, de 10 de setembro de 1824, a austríaca já demonstrava preocupação acerca das possíveis intrigas políticas que a chegada de Graham poderia despertar no palácio, fato que se concretizou. Como mostrarei nas páginas seguintes, a atuação de Graham como preceptora pode não ter sido duradoura. Porém, na tentativa frustrada de garantir uma educação melhor à princesa Maria da Glória, Maria Leopoldina ganhou uma grande amiga, com quem compartilharia muitas de suas dores e sofrimentos palacianos.

\section{O terceiro diário}

Segundo Akel, o texto sobre Dom Pedro I é mais um relato autobiográfico de Graham que o seu terceiro diário sobre o Brasil (AKEL, 2011, p. 193) devido à falta de datas precisas e ao fato de que os eventos recontados ali foram narrados à sua amiga. Para a biógrafa, o diário que Graham publicara em 1824 sobre o Brasil pode ser lido como dois relatos distintos em uma única edição, pois o Journal of a Voyage to Brazil é dividido em duas partes: a primeira inicia-se em 31 de julho de 1821, com a partida da fragata Doris da Inglaterra, e termina em 20 de abril de 1822 com a morte do marido da viajante, o capitão Thomas Graham, e com a chegada no Chile, onde permanece durante 11 meses e escreve o Journal of a Residence in Chile (2003); e a segunda parte, que começa em 13 de março de 1823 e estende-se até 18 de dezembro do mesmo ano, quando Graham narra o trajeto de volta para a Inglaterra, onde fica até julho de 1824 para supervisionar a publicação de seus diários no país e preparar os livros e materiais pedagógicos necessários para dar início às suas atividades como preceptora da princesa Maria da Glória. A terceira parte do diário seria, portanto, a narrativa ditada à Lady Caroline Fox entre 1834 e 1835, que compreende o período entre setembro de 1824, com a instalação de Graham no Palácio Imperial, e setembro de 1825, quando ela deixa o Brasil para voltar à Inglaterra. 
Apesar de considerar o relato sobre a terceira estada de Graham no Brasil como uma autobiografia, a própria Akel traça paralelos entre o Escorço biográfico e o Journal of a Voyage to Brazil. Ao contrário do segundo diário, no qual Akel aponta que Graham torna-se "afetuosamente elogiosa, celebra todos os aspectos da vida da corte e das políticas governamentais" (AKEL, 2011, p. 194, minha tradução ${ }^{7}$ ), no escrito sobre Pedro I, a voz narrativa da escritora passa a ser "rancorosa e inclusive agressiva em certos momentos", enquanto em outros "se compadece consigo mesma, mas também é capaz de perceber e transmitir os elementos ridículos que podem surgir, de vez em quando, nas situações mais sérias" (AKEL, 2011, p. 194, minha tradução ${ }^{8}$ ). Para a biógrafa de Graham, há igualmente, no segundo diário, uma redução nas descrições das paisagens pitorescas e da natureza para retratar os "eventos que ocorrem entre quatro paredes", porque Graham começa a circular, provavelmente por conta de sua estreita amizade com lorde Cochrane, nos ambientes da corte. Em contraste com essa segunda parte, no Escorço biográfico, nota-se uma narração mais onisciente, o que permite maior "liberdade para manipular a ação, interpretar os motivos dos demais personagens e controlar as cronologias textuais" (AKEL, 2011, p. 174, minha tradução9).

Embora Akel (2011) leve em conta o fato de que o manuscrito publicado postumamente tenha sido apenas ditado à amiga de Graham dez anos depois de ter vivido aqueles eventos no Brasil, ela não reflete sobre o próprio processo editorial pelo qual ambos os diários passaram até serem lançados na Inglaterra nem, tampouco, avalia a intimidade adquirida pela viajante com a sua amiga imperatriz ao longo de sua vivência dentro do Paço de São Cristóvão. Certamente há diferenças relevantes na linguagem empregada e no posicionamento da viajante como narradora na primeira e na segunda parte do Journal of a Voyage to Brazil em relação ao Escorço biográfico devido ao olhar retrospectivo da autora e ao falecimento de Leopoldina e de Dom Pedro I, como aponta Akel. Contudo, a biógrafa não leva em consideração algumas particularidades da composição dos dois relatos.

Enquanto Journal of a Voyage to Brazil e Journal of a Residence in Chile foram detalhadamente editados para publicação, o Escorço biográfico é um manuscrito inacabado e não há registros de que Graham tivesse interesse em publicá-lo, apesar de haver marcas de revisões nos originais, assinalados por Lacombe em sua edição. O que se pode afirmar é que o texto traduzido por Lacombe para o português parece estar em fase de execução, pois alguns trechos estão confusos e, por vezes, truncados, o que não acontece nos diários publicados oficialmente. Dada a parca revisão e edição do manuscrito, a leitura comparada desenvolvida por Akel (2011) parece limitada, visto que ela tira conclusões precipitadas e contrasta as reminiscências sobre Dom Pedro I como se fossem equivalentes aos diários sobre o Brasil e o Chile em termos editoriais. Além disso, há os distintos contextos de inserção de Graham no Brasil em Journal of a Voyage to Brazil e em O escorço biográfico, os quais são deixados de lado em sua análise.

Quando Graham chega ao Brasil em 1821, não é familiarizada com a cultura do país, apesar de estar a par de sua situação política para alcançar a independência. Nesses primeiros nove meses em terras brasileiras, a viajante testemunhou 
os conflitos em Pernambuco e na Bahia contra os portugueses, tendo inclusive acompanhado de perto o estado de sítio de Olinda por conta do levante independentista na província (GRAHAM, 2010, p. 31-58) e relata detalhadamente os eventos que culminaram no Dia do Fico, em janeiro de 1822, bem como as suas consequências que abalaram as relações entre Brasil e Portugal. Akel interpreta a narradora da primeira parte do diário como alguém que busca informar os seus leitores com imparcialidade e impessoalidade (AKEL, 2011, p. 173), ainda que suas atitudes variem entre uma superioridade moral, por conta de ser inglesa, $\mathrm{e}$ uma subordinação às figuras políticas eminentes que conhecera no Brasil, pelo fato de ser estrangeira (AKEL, 2011, p. 96-97).

É verdade que o cunho moralista de Graham em relação aos brasileiros e portugueses, principalmente às mulheres, é mais predominante no primeiro período de moradia no Brasil. Na Bahia, ela escreve que "o estado geral de educação é tão baixo que é requisito mais que talento e desejo para obtê-la” (GRAHAM, 2010, p. 82, minha tradução ${ }^{10}$ ), fazendo com que os homens que tiveram acesso aos livros fossem "por vezes um pouco vaidosos, sentindo-se muito acima de seus conterrâneos, e a porção de aprendizado por livros é pequena" (GRAHAM, 2010, p. 82, minha tradução ${ }^{11}$ ). No entanto, comentários semelhantes são tecidos pela viajante em sua segunda estada no país, como mostra a sua descrição da família Affonso, que possuíam um engenho o qual Graham visitara em agosto de 1823. Segundo Graham, há oito filhos, sendo quatro deles burros (dumb) e quatro inteligentes, "os burros e os falantes tendo nascido alternadamente" (GRAHAM, 2010, p. 203, minha tradução ${ }^{12}$ ).

Não há também, conforme argumenta Akel, a predominância de imparcialidade e neutralidade na narração de Graham sobre a sua primeira estada no Brasil. No prefácio do Journal of a Voyage to Brazil, Graham afirma que as circunstâncias políticas do país durante a sua visita "forçaram a escritora a pausar antes de submetê-lo à prensa, e a cancelar muitas páginas que registravam ocorrências tanto públicas quanto privadas" (GRAHAM, 2010, p. 5, minha tradução ${ }^{13}$ ). Ela admite que possa haver "uma demasiada natureza pessoal, mas o que é dito é, pelo menos, honesto" (GRAHAM, 2010, p. 5, minha tradução ${ }^{14}$ ), justificando, por fim, a sua ocasional falta de neutralidade:

A escritora não pretende perfeita imparcialidade, pois, em alguns casos, imparcialidade não é uma virtude; mas sabendo que nenhuma bondade humana possa ser obtida sem uma mistura de maldade, ela confia que um retrato justo das duas seja dado, embora tenha-se custado alguma dor para a sua escrita. (GRAHAM, 2010, p. 6, minha tradução ${ }^{15}$ ).

Ao reconhecer a parcialidade de seu relato, Graham também legitima a sua autoridade, pois sabe que seus escritos são baseados em sua própria interpretação desses eventos políticos que eram também de interesse dos ingleses. Inclusive, Graham, por vezes, ironiza a suposta neutralidade inglesa nos conflitos da independência. Se por um lado a Inglaterra não queria arriscar os acordos comerciais com Portugal estabelecidos em 1810, o país via na independência brasileira uma 
oportunidade de criação de novos mercados e, sobretudo, de findar o tráfico de escravos para a instituição da mão de obra livre e, consequentemente, a expansão do capitalismo industrial. Um exemplo ocorre em seus relatos do início de janeiro de 1822 sobre o Dia do Fico e os seus desdobramentos. No dia 10, um dia depois de Pedro I anunciar oficialmente que permaneceria no Brasil, Graham escreve:

Hoje nossos amigos comerciantes estão sob novo alarme e fizeram um requerimento formal ao capitão para permanecerem. Com aquele espírito mesquinho que se passa por diplomático, o vice-cônsul e os comerciantes, ao invés de dizerem do que eles têm medo, dizem somente, "Senhor, nós temos medo, circunstâncias nos fazem assim, e nós esperamos que vocês fiquem até" etc. etc. [...] Eu não me preocupo agora com seus relatórios oficiais, os quais eu percebo que são folhas grandes de papel, grandes carimbos, sem palavra alguma que não possa ser publicada em qualquer parede de igreja, para os seus fornecedores de leite e de água, mas os quais eu considero absurdos e maliciosos, porque eles tendem a excitar desconfiança e alarme onde não há perigo. A verdade agora é que pode haver algum motivo para medo, se eles ao menos o expressassem abertamente. Eles falam em carregar o Príncipe à força para Lisboa, e assim fazê-lo obedecer às Cortes apesar dos brasileiros; e ambas as partes são tão violentas que elas provavelmente lutarão. Nessa luta haverá, sem dúvida alguma, perigo à propriedade estrangeira; mas por que não falar isso? Por que não falar que esse é o caso? (GRAHAM, 2010, p. 114, minha tradução ${ }^{16}$, grifo no original).

Nesse trecho, a viajante critica abertamente a dissimulação de neutralidade dos ingleses acerca da decisão de Dom Pedro de continuar no Brasil, quando, na verdade, os comerciantes britânicos tinham medo de que suas propriedades fossem depredadas. Ela debocha da linguagem oficial dos documentos diplomáticos ao afirmar que não passam de palavras com caráter supostamente virtuoso, mas que empenham o papel de incitar ainda mais os ânimos tanto dos portugueses quanto dos brasileiros. Claramente irritada, o trecho sugere que, para Graham, não seria o temor dos ingleses de perder dinheiro que deva justificar a intervenção nesses conflitos, ainda que estes sejam violentos.

Os comerciantes e diplomatas britânicos queriam evitar que a fragata deixasse o Rio de Janeiro até que outros navios chegassem para reforço, caso houvesse, de fato, uma guerra. Graham não opunha a permanência no porto carioca, mas era contra a defesa dos interesses ingleses em prol da possibilidade de independência do Brasil, para a qual ela mesma parecia vibrar. Ela demonstra simpatia à aparição pública de Dom Pedro I e Maria Leopoldina no Teatro Nacional no Dia do Fico, onde foram aplaudidos pela decisão, e reproduz integralmente o discurso de Bernardo Carvalho defendendo a implementação da Assembleia Constituinte e um império luso-brasileiro, no qual o Brasil seria regido pelo príncipe. Para os brasileiros, como Graham bem sabia, a inclinação de Dom Pedro por valores liberais, pelo menos naquele momento, poderia resultar na independência do país de Portugal.

Na noite de 11 de janeiro, quando tropas portuguesas remanescentes no Brasil depois da volta de Dom João VI para Portugal revoltaram-se e pretendiam for- 
çar o príncipe a retornar a Portugal, Graham descreve cenas de medo e terror entre os membros da corte e a elite política apoiadora do príncipe, que corriam para suas casas a fim de proteger suas riquezas. Deixando o Rio de Janeiro em clima de guerra, as tropas comandadas pelo general português Jorge de Avilez tomaram as ruas da cidade enquanto Pedro I e dona Leopoldina assistiam a um concerto no Teatro Nacional. Durante a madrugada, Dom Pedro consegue garantir a fuga de Leopoldina, que estava grávida e perdeu o bebê durante esse percurso, e seus dois filhos para uma fazenda em Santa Cruz. No dia 13 de janeiro, Graham relata em seu diário que o príncipe perguntou ao capitão Graham se ele cederia a sua fragata para a proteção dele e de sua família:

A resposta é, claro, que, embora o navio deva observar a mais rígida neutralidade entre as partes, [...] que nós já estamos prontos para receber e proteger a Princesa e as crianças, e também, caso ele tenha motivos para apreender perigo pessoal, o próprio Príncipe. Minha cabine está, de todo modo, pronta. (GRAHAM, 2010, p. 119, minha tradução ${ }^{17}$ ).

Percebe-se novamente que, a despeito da recomendação oficial de neutralidade, havia uma inclinação política da própria viajante de apoio às causas brasileiras e de Dom Pedro. Quando a inglesa volta em março de 1823 após sua estada no Chile, o Brasil já se tornara independente, mas ainda em plena convulsão política pelas disputas internas de poder e com as expectativas da abertura da Assembleia Constituinte em maio do mesmo ano. Os comentários políticos da viajante continuam a todo vapor na segunda parte de Journal of a Voyage to Brasil, mas agora são informados, principalmente, por sua convivência com lorde Cochrane, por sua amizade com José Bonifácio e sua família e pela amizade iminente com a imperatriz Leopoldina.

Como argumenta Akel, a aproximação de Graham da corte brasileira certamente influenciou os elogios à família imperial, com quem gostaria de se relacionar desde o início desse período no país. Em maio de 1823, a viajante dissera ao então ministro José Bonifácio que gostaria de servir Leopoldina, dado o caráter gentil da imperatriz e o fato de que a inglesa se sentira desprotegida na corte, visto que agora era uma mulher viúva no Brasil (GRAHAM, 2010, p. 177). Bonifácio, que tinha amizade com a austríaca, conversou com ela, que prontamente marcou um encontro com Graham: as duas logo tornaram-se grandes amigas. Em visita ao paço em 23 de julho, a viajante é convidada para adentrar a câmara onde Dom Pedro se reunia com os novos ministros, e o imperador faz questão de conversar com ela sobre frivolidades. Sobre a imperatriz, Graham não poupa elogios: "ela é em todos os respeitos uma mulher amável e respeitável [...] suas conquistas pessoais ornariam o status de uma dama particular; seu temperamento, prudência e coragem estão de acordo com a sua alta posição" (GRAHAM, 2010, p. 191, minha tradução ${ }^{18}$ ).

Interessante notar que na entrada que precede esse encontro, datada de 18 de julho, Graham tece comentários sobre a renúncia de José Bonifácio do Ministério do Interior e dos Negócios Estrangeiros, lamentando a saída do político 
de seu posto e atribuindo o ocorrido à carta provinda de São Paulo, com 300 assinaturas, pedindo a demissão de Bonifácio e seus irmãos por conta da perseguição de membros da assembleia (GRAHAM, 2010, p. 188-189). A inglesa claramente apoia Bonifácio e os seus irmãos, mas não faz nenhuma crítica a Dom Pedro por acatar a decisão. Porém, na edição de Journal of a Voyage to Brazil de 2010, as editoras Jennifer Hayward e Maria Soledad Caballero incluíram trechos que Graham pretendia acrescentar ao seu relato para uma segunda tiragem, que nunca ocorreu. Nesse excerto, ela culpa a influência da amante do imperador, Domitila de Castro, e um dos principais conselheiros de Dom Pedro, Plácido Antônio Pereira de Abreu, que era barbeiro do imperador quando ele ainda era príncipe e que foi promovido a chefe da Real Ucharia e, mais tarde, a tesoureiro de Maria Leopoldina. Segundo Isabel Lustosa, era comum que Pedro I elevasse os cargos de seus criados a posições de governo (LUSTOSA, 2006, p. 62-67). Conforme a frase de Lady Callcott citada no início deste artigo, o barbeiro Plácido era um dos "aduladores profissionais" que intervinham na política brasileira. Em companhia da amante Domitila, Plácido e outro criado, conhecido como Chalaça, teriam a total confiança do imperador e criariam "um ambiente hostil em torno de d. Leopoldina" (LUSTOSA, 2006, p. 197).

Esses comentários não foram publicados em Journal of a Voyage to Brazil, mas somente no Escorço biográfico e na versão revisada por Graham que nunca foi lançada. A preferência da viajante por não incluir essas informações pode ser interpretada, como o fez Akel, como oportunismo de Graham para garantir a sua boa relação com a família imperial (AKEL, 2011, p. 96), pois a viajante, já confirmada como preceptora de Maria da Glória, não queria arriscar a sua reputação com a publicação de seu diário. É verdade que Graham pudesse já ter escutado os rumores sobre a relação do imperador com Domitila, sobre as suas arbitrariedades e a sua vulgaridade no trato diário com os membros da corte durante a sua segunda estada no país. Porém, Graham não poderia ter escrito sobre isso na segunda parte de Journal of a Voyage to Brazil, porque, além de perder a oportunidade para ocupar o cargo e permanecer no Brasil como queria, a narração de tais intrigas inviabilizariam a credibilidade e a autoridade que ela pretendia consolidar com os diários sobre a América do Sul. Enquanto o seu primeiro relato de viagem, Journal of a Residence in India, publicado em 1813, apresentava Graham mais como reformadora social e mera observadora, nos diários da América do Sul, nota-se um ensejo autoral de inserir-se como protagonista e legitimar-se como autoridade intelectual, posição que poderia ser minada com a exposição dos rumores palacianos que escutava no Rio de Janeiro. Deve-se ressaltar também que, à época da edição de seu diário sobre o Brasil, a amizade da inglesa com Leopoldina ainda era incipiente e muito provavelmente Graham não apreendia a gravidade das circunstâncias com as quais a imperatriz lidava diariamente.

Essa supressão também pode estar associada às próprias práticas editoriais de relatos de viagem. Como explicam Innes Keighren, Charles Withers e Bill Bell, era comum que os viajantes da editora de John Murray se correspondes- 
sem com seus editores a fim de comunicar as informações que coletavam em campo para que depois elas fossem organizadas em forma de diário; era crucial saber "como e onde tal escrita ocorreu, qual era o propósito do autor [...] e [...] os motivos por trás de emendas posteriores" (KEIGHREN; WITHERS; BELL, 2015, p. 11, minha tradução ${ }^{19}$ ).

Segundo Keighren, Withers e Bell (2015), havia sempre o cuidado em decidir como e o que deveria ser relatado, até porque muitas das narrativas de viagem eram produzidas durante as missões coloniais e financiadas pelo governo britânico. No caso de Graham, ela tinha um contrato direto com a casa de John Murray e não era enviada oficial do império. Contudo, o seu marido era, sim, o capitão da fragata Doris que estava em missão oficial na América do Sul justamente para acompanhar os conflitos políticos e processos de independência do Brasil e do Chile.

Além de seu cargo como educadora das princesas, tais circunstâncias poderiam ter levado Graham a ser cuidadosa com as palavras que empregava para não se comprometer posteriormente com o governo inglês, que só reconheceria a independência do Brasil oficialmente em fevereiro de 1825. Os detalhes sórdidos da vida palaciana, como as intrigas de Domitila de Castro e os seus favoritos, seriam revelados somente dez anos mais tarde no Escorço biográfico e, mesmo assim, se tornariam públicos apenas no século XX.

\section{A vida doméstica do palácio}

Como mencionado anteriormente, os escritos de Lady Callcott sobre Dom Pedro I apresentam traços de revisão, embora não haja evidência de que havia interesse de Graham em publicá-lo. Como aponta o diretor da Biblioteca Nacional à época da publicação on-line do manuscrito, Rodolfo Garcia, em sua explicação: "A avaliar pelos trechos cancelados no manuscrito, é de supor que aquela memória não tivesse alcançado redação definitiva, com a disposição de matérias que devia prevalecer e a divisão em capítulos que se fazia necessária" (GARCIA, 1997, p. 22). Sendo assim, não se pode analisar a forma desse relato como a que se apresenta nos diários sobre o Brasil e sobre o Chile, que foram cuidadosamente revisados e editados por Graham e por John Murray II. Akel alega que Lady Callcott manipula os escritos sobre a sua terceira estada no Brasil "para acomodar situações, acontecimentos e inclusive sequências temporais à sua mensagem principal, que era a sua total inocência" (AKEL, 2011, p. 195, minha tradução $0^{20}$ ). Para a biógrafa, os eventos narrados são de pouca credibilidade, servindo somente para defender a honra da viajante e esclarecer a sua saída repentina do palácio.

Essa não é a interpretação da biógrafa de Dom Pedro I, a historiadora Isabel Lustosa, que apreende o Escorço biográfico como um testemunho legítimo da vida doméstica no Paço Imperial. Baseada também em outros documentos históricos, como cartas de viajantes, membros da corte imperial e oficiais do governo, Lustosa demonstra que é um consenso o domínio da concubina Domitila de Castro sobre o imperador e sobre a corte, relegando Maria Leopoldina a uma "situação de quase prisioneira, isolada e constantemente vigiada em sua própria 
casa" (LUSTOSA, 2006, p. 212). Mais que justificar a sua demissão do cargo de preceptora, o texto de Graham sobre Dom Pedro elucida a triste situação de sua amiga imperatriz.

Paulo Rezzutti igualmente utiliza tanto Diário de uma viagem ao Brasil $^{21}$ quanto o Escorço biográfico como fontes históricas em suas biografias sobre Dom Pedro (REZZUTTI, 2015), Leopoldina (REZZUTTI, 2017) e Domitila de Castro (REZZUTTI, 2013). Inclusive, Rezzutti aponta falhas na descrição que Callcott faz em seu terceiro relato sobre o pai e a família de Domitila. Graham escreve que João de Castro, "um português de boa família", teria aproveitado a hospedagem de Dom Pedro em sua loja, quando este passou por São Paulo por conta de assuntos políticos, para apresentar as suas quatro filhas solteiras "para entreter o Real visitante com música e dança". Segundo a inglesa, estava ausente "a pérola da família”, Domitila, cuja presença se fez tão necessária que seu pai mandou buscá-la (CALLCOTT, 1997, p. 80). Rezzutti afirma que "[d] a fofoca recolhida por Lady Graham, [...] a única verdade é que o pai de Domitila era um português de boa família" (REZZUTTI, 2013, p. 27). É provável que esse lapso se deva ao fato de que Graham teria escutado a história da concubina através dos relatos de Leopoldina. No entanto, ainda assim, Rezzutti frequentemente recorre aos testemunhos da viajante, principalmente para descrever o contexto sociocultural, histórico e político da época e também o próprio desgaste psicológico de Leopoldina com a ascensão social de Domitila na corte.

O caso de Pedro I com Domitila começara em agosto de 1822 e duraria sete anos. Originalmente de São Paulo, a amante e sua família foram transferidas para o Rio de Janeiro e, em 1824, para o Paço de São Cristóvão, onde Domitila e sua irmã Ana Cândida tornaram-se damas de companhia do Paço. Em 1825, Dom Pedro eleva sua amante a dama camarista de Leopoldina, obrigando sua esposa a conviver diariamente com ela. No ano seguinte, confere a Domitila o título de viscondessa e, posteriormente, de marquesa de Santos. Nas palavras do comerciante inglês John Armitage:

Ao mesmo tempo o seu tratamento para com a infeliz imperatriz era o mais insensível. Enquanto prodigalizava de graças à nova marquesa, e ela distribuía mercês por suas mãos, aquela que era filha da augusta descendência da casa de Habsburgo, apesar de ser pouco dispendiosa, estava reduzida a solicitar de seus fâmulos empréstimos e dinheiro (ARMITAGE apud LUSTOSA, 2006, p. 197).

Tal testemunho é confirmado, segundo Lustosa, pelas inúmeras cartas de Maria Leopoldina pedindo empréstimos. Rezzutti, no entanto, afirma que essas dívidas tiveram início já nos primeiros momentos do seu casamento, pois Dom Pedro I sempre regulou as despesas de sua esposa. Em uma carta ao pai de setembro de 1820, Leopoldina alega que o príncipe regente não lhe pagava o seu dinheiro mensal "quando isso ocorre, meu esposo o retém e não posso tirá-lo porque necessita dele para si mesmo" (MARIA LEOPOLDINA apud REZZUTTI, 2017, p. 3964). Essas dívidas tornaram-se mais acentuadas ao longo dos anos, 
principalmente porque "além de não ter dinheiro, d. Leopoldina ainda era roubada pelos próprios cortesãos" (REZZUTTI, 2017, p. 3987).

No relato de Callcott, ela copia na íntegra uma carta da imperatriz enviada após a sua saída no palácio, na qual dona Leopoldina pede que aceite seus "oferecimentos", ou seja, pagamentos por seus serviços. Em nota de rodapé, a inglesa observa que a imperatriz oferecera a ela dinheiro, porque sabia que "Plácido, ainda que recebesse de seu amo a quantia que [lhe] era devida [por sua] estada no Paço, nunca [lhe] havia dado o montante, e que nem os livros que [...] trouxera, nem qualquer outra despesa, lhe havia sido paga" (CALLCOTT, 1997, p. 105). Como tesoureiro de Maria Leopoldina e aliado aos interesses de Domitila, Plácido aparentemente desviava recursos dos cofres da imperatriz, deixando-a com escassas quantias.

Callcott narra também o isolamento de Leopoldina e passa a ser a principal aliada da imperatriz, que via na inglesa uma confidente para as suas destrezas. Sobre o cotidiano em São Cristovão, ela conta que era regra que a parte do palácio onde viviam a preceptora, a princesa Maria da Glória e a imperatriz "devesse fechar a cada tarde muito cedo, e não abrir senão pouco depois do nascer do sol" (CALLCOTT, 1997, p. 90), enquanto o resto da corte gozava de festas e jantares até tarde da noite. As refeições de dona Leopoldina eram servidas "numa mesinha pequena, numa espécie de quarto de passagem, mobiliado todo em volta com malas fechadas que ela havia trazido de Viena". Nessas malas, estavam os "vestidos que a sociedade do Brasil não exigia, livros, que ela não tinha nem oportunidade nem espaço para arrumar [...] e instrumentos para prosseguir no estudo de filosofia natural e experimental que ela muito apreciava" (CALLCOTT, 1997, p. 92). Após o seu jantar, segundo a viajante, Leopoldina acompanhava a refeição de seu marido e, somente depois de cumprir essa tarefa, é que podia sentar-se para conversar com sua amiga:

A princípio ela costumava mandar-me chamar ao seu apartamento, mas como lá não podíamos fiar sem alguns acompanhantes, cujas narrativas da familiaridade com que ela me tratava excitavam violentos ciúmes entre as damas, ela preferiu, após três ou quatro dias, que eu ficasse depois do jantar em meu próprio quarto até que ela pudesse procurar-me (CALLCOTT, 1997, p. 93).

A constante vigilância e tramas contra a imperatriz impediam-na de sentir-se confortável em sua própria casa. Inclusive foram esses "violentos ciúmes" que desencadearam os desentendimentos e desconfiança de Dom Pedro acerca de Graham. O fato de ser estrangeira levantava suspeitas, segundo Rezzutti, não somente nos membros da corte, mas também em outras figuras políticas, como o embaixador da França no Brasil que "tinha-a por espiã e [...] informou em despacho para Paris que [Graham] havia sido expulsa por ter tentado se imiscuir na política" (REZZUTTI, 2017, p. 5977). Além de ser hostilizada por ser estrangeira em meio da corte, o fato de ter se recusado a participar de certas cerimônias, como a de beija-mão ${ }^{22}$, teria contribuído para causar desconforto nas damas e 
nos criados, que já eram muito familiarizados com os costumes da corte portuguesa. Quando uma criada diz à viajante, de forma debochada, que teria um vestido para emprestar-lhe para a cerimônia, Graham responde categoricamente "que não teria uniforme porque não sendo Criada do Paço, [...] iria de certo com [seu] vestido à moda inglesa" (CALLCOTT, 1997, p. 98, grifo no original). As damas de guarda-roupa e o barbeiro Plácido já haviam ridicularizado suas roupas no dia de sua chegada, quando Graham desfazia as suas malas.

Na ocasião em que a viajante revida a hostilidade, coloca "todos os seguidores dos Bragança em ebulição e na manhã seguinte iniciaram o que pretendiam ser uma severa punição à insolência de uma estrangeira que ousava rejeitar a servidão, mesmo no Palácio Imperial" (CALLCOTT, 1997, p. 98). Na ausência da imperatriz e do imperador, as damas de companhia e os criados da princesa Maria da Glória, com o apoio do barbeiro Plácido, recusam-se a preparar e servir o café da manhã da menina. O episódio, relatado de forma confusa na narrativa de Callcott, resulta num paroxismo de Dom Pedro que, pelas mãos de Leopoldina, entrega um bilhete ordenando que a preceptora "se confinasse ao [seu] próprio apartamento, a não ser quando fosse chamada a dar lição à princesa, ou passear com as irmãs pelo jardim". Incrédula, a escritora relembra os seus sentimentos de forma rancorosa: "sentei-me e chorei tão sinceramente quanto a Imperatriz, que me disse estar certa da minha inocência" (CALLCOTT, 1997, p. 99). Segundo Callcott, a imperatriz estava inconsolável e aconselhou sua amiga a deixar o seu posto, pois, apesar de ter sua amizade em alta estima, não poderia obrigar-lhe a permanecer naquele lugar onde ela mesma levara a vida "de um prisioneiro de Estado e ainda submetida a todas as espécies de impertinências e indolências por parte de pessoas da mais baixa extração" (CALLCOTT, 1997, p. 100), como o barbeiro Plácido e as criadas do paço.

Para Leopoldina, os seus inimigos voltaram-se igualmente contra Graham e não havia nada que ela pudesse fazer. Com a ajuda da imperatriz, a inglesa escreve uma carta de demissão a Dom Pedro, copiada na íntegra em seu relato, na qual critica veementemente a notificação do imperador e se recusa a ser "tratada como uma criada" (CALLCOTT, 1997, p. 101). Na noite de sua demissão, a imperatriz chega a instruir Graham a não comer nada que lhe fosse oferecido, alegando que havia "no Palácio pessoas tão malvadas [que] era certo que ela havia perdido seu secretário alemão, no qual tinha muito grande confiança, por envenenamento" (CALLCOTT, 1997, p. 104), acusação que jamais fora comprovada.

Apesar de narrar alguns eventos históricos e políticos do Brasil e alguns passeios que realizou depois de sua saída do Paço de São Cristóvão, uma considerável parte do relato de Callcott sobre Dom Pedro sugere uma espécie de defesa de dona Leopoldina e a exposição da crueldade e possessividade de Dom Pedro em relação à sua esposa. A viajante tenta balancear essa imagem do imperador com episódios que mostram que ele tentara apaziguar os ânimos e demonstrar generosidade e apreciação por seus serviços. Talvez o maior deles seja a sua intervenção perante os criados, que, sob orientação do barbeiro Plácido, teriam dificultado ao máximo que Graham conseguisse levar consigo seus pertences ao impedir 
o uso de qualquer meio de transporte sob a justificativa de que todos estariam indisponíveis. A ira do imperador teria impulsionado que Plácido providenciasse imediatamente o carro da princesa Maria da Glória durante uma semana para a viajante realizar sua mudança (CALLCOTT, 1997, p. 104). Além dessa atitude favorável, Lady Callcott conta que Dom Pedro sempre fazia questão de lhe cumprimentar em público, independente da ocasião. Seria essa cortesia uma forma de manter as aparências para o povo, que estava cada vez mais estupefato com o comportamento do imperador em relação à imperatriz?

Segundo Lustosa, não era nenhum segredo que Dom Pedro tinha um caso com Domitila, pois, quando se tornou primeira-dama camarista de dona Leopoldina, não era raro que o imperador aparecesse em público com as duas mulheres, até mesmo em compromissos oficiais (LUSTOSA, 2006, p. 191-195; p. 211-218). As aparições públicas e a obtenção de elevados títulos na corte causaram problemas diplomáticos para Dom Pedro, pois a ascensão social e política de Domitila "[colocavam-na], senão em pé de igualdade com Leopoldina, com uma aproximação muito grande do trono e seus favores, o que acabou por descompensar o poder da casa imperial" (REZZUTTI, 2017, p. 5793). Lady Callcott reproduz algumas cartas que comprovam o crescente desgosto de sua amiga com a situação, como a de novembro de 1824, reproduzida integralmente no relato, na qual a imperatriz se diz "acostumada a resistir e a combater os aborrecimentos", mas confessa "somente a vós, que cantarei um louvor ao Onipotente quando me tiver livrado de certa canalha" (MARIA LEOPOLDINA apud CALLCOTT, 1997, p. 123, grifos no original) Infelizmente esses desprazeres persistiriam pelo resto de sua vida.

Em 1826, Dom Pedro reconheceu oficialmente sua filha com Domitila, Isabel Maria, conferindo a ela o título de duquesa de Goiás. Ele insistia que a pequena fosse criada junto às irmãs, causando grande insatisfação para Leopoldina. Da última vez que Graham visitara sua amiga em 8 de setembro de 1825, pouco antes de retornar à Inglaterra, a encontrou "fraca de saúde, e com maior depressão de ânimo que de costume" (CALLCOTT, 2006, p. 140). De acordo com depoimentos da época, a imperatriz cuidava cada vez menos de sua aparência:

Se nos anos anteriores houve quem lhe destacasse a elegância, nos dois últimos anos de vida seu aspecto tornou-se totalmente desleixado. Andava quase sempre vestida de amazona, e para sair usava botas grosseiras ornadas com grandes esporas sem brilho, iguais às que são usadas pelos mineiros. Enrolava-se num casaco enorme e desgracioso, colocava um chapéu de homem e assim vestida montava seu cavalo, cavalgando por toda a cidade (LUSTOSA, 2006, p. 234).

Com o passar do tempo, sua saúde degradara de tal forma que tinha intensas dores no corpo e ataques de choro. $\mathrm{O}$ estopim de sua tristeza deu-se quando Dom Pedro passou um mês fora de casa por conta do adoecimento do pai de Domitila. Leopoldina escreveu-lhe uma carta pedindo que ele escolhesse uma das duas mulheres e, se optasse pela amante, gostaria de retornar à Áustria para estar junto de seu pai e sua família. Furioso com o ultimato, o imperador voltou 
para casa, onde discutiram violentamente, e ordenou que cortassem pela metade os recursos para a alimentação da imperatriz e lhe tirassem os cavalos para suas cavalgadas (LUSTOSA, 2006, p. 236). Quando dona Leopoldina se recusou a aparecer publicamente com Domitila para assumir a regência enquanto Dom Pedro estivesse em viagem no sul do país, o imperador "tentou arrastá-la, e consta que nessa ocasião a teria machucado" (LUSTOSA, 2006, p. 238).

Esse episódio piorou o seu estado de saúde e, mesmo em seu leito de morte, a imperatriz não teve paz, pois a concubina tentara de diversas formas adentrar o seu quarto, tomada pela cólera causada pela hostilidade com que era tratada pelo povo, que tomou as dores da austríaca, visto que "era do conhecimento público a situação de pobreza, isolamento e abandono em que vivia d. Leopoldina" (LUSTOSA, 2006, p. 240). Lady Callcott termina o seu relato com a narração dessa morte e as suas consequências, como o afastamento de Domitila, a esta altura já conhecida como marquesa de Santos. Em seu último parágrafo, admite que foi doloroso relembrar e recontar tais eventos sobre o imperador, que acabara de falecer. Contudo, a inglesa justifica seus defeitos "devido aos maus exemplos - uma educação viciosa, condições políticas aflitivas e difíceis, e uma corte ignorante, grosseira e mais que corrompida" (CALLCOTT, 1997, p. 147) e tenta ressaltar sua coragem em ter tornado possível o surgimento do Brasil como nação.

Pode-se dizer, de fato, que as caracterizações das figuras históricas retratadas por Graham no Escorço biográfico sejam limitadas aos padrões dos heróis (a própria viajante e sua amiga imperatriz), que devem superar obstáculos impostos por vilões (Domitila, barbeiro Plácido e Dom Pedro) para provarem o seu caráter virtuoso, como sugere Akel (2011). No entanto, a leitura da biógrafa de que tais eventos seriam meramente criações ficcionais pelas quais "a misteriosa narradora vai crescendo ao longo das páginas até converter-se em alguém maior que sua história” (AKEL, 2011, p. 213, minha tradução ${ }^{23}$ ) é infactível. Primeiramente pelo fato de que o posicionamento de Callcott como testemunha dos eventos é exatamente o que garante ao texto autoridade e autenticidade. Em Journal of a Voyage to Brazil, estratégias semelhantes são empregadas, pelas quais a viajante recorre à narração de situações de perigo comuns às histórias de aventura para preconizar a sua própria coragem. Como explicam Keighren, Withers e Bell, esse recurso era frequente entre autores de literatura de viagem e buscava justamente consolidar autoridade, pois o reconhecimento da posição de um viajante ou explorador "dependia em como se regulava as próprias experiências, superava uma natureza adversa, nativos suspeitos ou fragilidade pessoal para explorar, viajar e escrever" (KEIGHREN; WITHER; BELL, 2015, p. 61, minha tradução ${ }^{24}$ ). No Escorço biográfico de Dom Pedro, essas trágicas aventuras configuram-se dentro da esfera doméstica, que, muitas vezes, era a própria origem das conspirações palacianas.

\section{Conclusão}

Ainda que pouco conhecido, o Escorço biográfico de Dom Pedro I está longe de ser um registro ficcional sobre a vida palaciana. É possível, no entanto, argu- 
mentar que, como ocorre em seus diários de viagem, Lady Callcott tenha recorrido a recursos da ficcionalidade, como a caracterização de personagens como vilões ou heroínas, a disposição de elementos das histórias de aventura que configuram perigo e adversidade e a superação de obstáculos para provar a virtuosidade, para compor sua narrativa. Essas técnicas certamente não diminuem o valor histórico e documental desse manuscrito, que é amplamente consultado em pesquisas sobre Dom Pedro I, Dona Leopoldina, Domitila de Castro e o cotidiano do palácio.

Além do breve relato sobre sua vida como preceptora no Paço de São Cristóvão, os próprios relatos de viagem de Maria Graham sobre o Brasil são fontes relevantes para apreender o caráter de Dom Pedro e os seus feitos na história brasileira. Enquanto Journal of a Voyage to Brazil possa ser compreendido como uma representação primordialmente do político e homem público, o Escorço biográfico oferece uma perspectiva íntima e quase personalista do imperador, que é exposto por sua crueldade e perversidade. $\mathrm{O}$ acesso à esfera doméstica é considerado um espaço frequentemente representado pelas mulheres viajantes (LEITE, 1984; GAZZOLA, 2008), mas nem sempre são interpretados por elas como ambientes de subserviência e passividade, como acontece nos registros de Maria Graham. Para a viajante, esses espaços, muitas vezes, sediam e promovem grandes articulações políticas, bem como o declínio de um império.

Notas

1. Esta pesquisa foi realizada com o apoio da Fundação de Amparo à Pesquisa do Estado de São Paulo entre dezembro de 2019 e novembro de 2020, durante estágio de pós-doutorado na Universidade de São Paulo.

2. No original: "never again could that active gallant figure join the world of men and women in eager talk and exchange of ideas, outside the four walls of her own home" (GOTCH, 1937, p. 283).

3. O manuscrito original em língua inglesa não pôde ser consultado e, portanto, todas as citações do Escorço Biográfico de Dom Pedro foram retiradas da edição traduzida por Américo Jacobina Lacombe, publicado em 1997 pela editora Itatiaia, juntamente com o conjunto de correspondências entre Maria Graham e a imperatriz Leopoldina. Além desta edição, a Biblioteca Nacional publicou a tradução de Lacombe e a troca epistolar da viajante com a imperatriz em versão digital, disponibilizada no seguinte link: http://objdigital.bn.br/acervo_digital/ div_obrasgerais/drg1305313.pdf (acessado em janeiro de 2021).

4. Em sua vida, a inglesa utilizou dois nomes autorais: Maria Graham e, quando se casou pela segunda vez, Maria Callcott. O Escorço biográfico de Dom Pedro I foi assinado com o último, enquanto os seus diários de viagem sobre o Brasil e Chile levam o primeiro. Ao longo de meu artigo, farei referência aos dois nomes, tendo em vista que, quando viveu no Brasil e conheceu Dom Pedro, a autora assinava como Maria Graham, mas quando escreveu suas memórias sobre o imperador, apresentava-se com seu segundo nome, Maria Callcott.

5. No original: "la libertad de entregar su propria versión del suceso, ya que tanto la Emperatriz como el Emperador habian fallecido".

6. No original: "mantener su importancia como protagonista".

7. No original: "celebra todos los aspectos de la vida de la corte y de las politicas gubernamentales". 
8. No original: "rencorosa e incluso agresiva por momentos; en otros, se compadece a sí misma, pero también es capaz de percibir y transmitir los elementos ridículos que pueden surgir, de vez em cuando, em las situaciones más serias."

9. No original: "libertad para manipular la acción, interpretar los motivos de los demás personajes, y manejar las cronologías textuales."

10. No original: "the state of general education is so low, that more than common talent and desire of knowledge is requisite to attain any".

11. No original: "sometimes a little vain, feeling themselves so much above their fellowcitizens, and the portion of book-learning is small".

12. No original: "the dumb and the speakers being born alternately".

13. No original: "forced the writer to pause before she committed it to press, and to cancel many pages recording both public and private occurrences".

14. No original: "too much of a personal nature, but what is said is at least honest".

15. No original: "The writer does not pretend to perfect impartiality, for in some cases impartiality is no virtue; but knowing that no human good can be attained without a mixture of evil, she trusts that a fair picture of both has been given, although it has cost some pain in the writing."

16. No original: "To-day our friends the merchants are under fresh alarm, and have made a formal request to the captain to stay. With that petty spirit which passes for diplomatic, the deputy-consul and merchants, instead of saying what they are afraid of, only say, "Sir, we are afraid, circumstances make us so, and we hope you will stay till" etc. etc. [...] I do not trouble myself now about their official reports, which I perceive are large sheets of paper, and large seals, without one word that might not be published on every church wall, for their milk and water tenor, but which I consider as absurd and mischievous, because they tend to excite distrust and alarm where no danger is. The truth is now, that there might be some cause of fear, if they would openly express it. They talk of carrying the Prince by main force to Lisbon, and so making him obey the Cortes in spite of the Brazilians; and both parties are so violent, that they will probably fight. In that fight there will doubtless be danger to foreign property; but why not say so? Why not say such is the case?"

17. No original: "The answer, of course, is, though the ship must observe the strictest neutrality between the parties, [...] that we are ready at once to receive and protect the Princess and children, and also, whenever he has reason to apprehend personal danger, the Prince himself. My cabin is therefore ready".

18. No original: "she is in all respects an amiable and respectable woman [...] her personal accomplishments would adorn the station of a private gentlewoman; her temper, prudence, and courage, fit her for her high situation" (GRAHAM, 2010, p. 191).

19. No original: "how and where such writing took place, what the author's purpose was $[\ldots]$ and $[. .$.$] the reasons behind later emendations of it."$

20. No original: "para acomodar situaciones, acontecimientos e incluso secuencias temporales a su mensaje principal, el cual era su total inocencia".

21. É importante ressaltar que Rezzutti consultou a tradução brasileira de Journal of a Voyage to Brazil, que foi realizada por Américo Jacobina Lacombe, publicada em 1990 pela Editora Itatiaia. Nessa edição, Lacombe traduziu a edição original do relato e não a sua mais recente versão com trechos inclusos por Graham posteriormente, que foi lançada por Hayward e Caballero (2010).

22. Costume da monarquia portuguesa que consistia no contato direto entre o imperador e seus vassalos, que rodeavam a figura eminente para beijar-lhe a mão.

23. No original: "la misteriosa narradora va creciendo a lo largo de las páginas hasta convertirse em alguien más grande que su historia." 
24. No original: "depended on how one regulated one's experiences, overcame an adverse nature, suspicious natives, or personal frailty, in order to explore, travel and write."

Referências

AKEL, R. María Graham. Una biografía literaria. Santiago: Editorial Universitaria, 2011.

CALLCOTT, M. Escorço biográfico de Dom Pedro I, com uma notícia do Brasil e do Rio de Janeiro em seu tempo. In: GRAHAM, M. Correspondência entre Maria Graham e a imperatriz Leopoldina. Tradução de Américo Jacobina Lacombe. Belo Horizonte: Editora Itatiaia, 1997, p. 59-147.

COSTA, C. "Apresentação". In: GRAHAM, M. Escorço biográfico de Dom Pedro I. Tradução de Américo jacobina Lacombe. Cadernos da Biblioteca Nacional, n. 7. Rio de Janeiro: Fundação Biblioteca Nacional, 2010, p. 7-16.

GARCIA, R. "Explicação". In: GRAHAM, M. Correspondência entre Maria Grahame a imperatriz Leopoldina. Tradução de Américo Jacobina Lacombe. Belo Horizonte: Editora Itatiaia, 1997, p. 11-26.

GAZZOLA, A. L. A. O Brasil de Marianne North: lembranças de uma viajante inglesa. Estudos Feministas, Florianópolis, v. 16 n. 3, p. 1031-1045, set.-dez., 2008. DOI: https://doi.org/10.1590/S0104-026X2008000300020.

GOTCH, R. B. Maria, Lady Callcott: the Creator of "Little Arthur". Londres: John Murray, 1937.

GRAHAM, M. Journal of a Residence in India. Edinburgo: Archibald Constable and Company, 1813.

GRAHAM, M. Diário de uma viagem ao Brasil. Tradução de Américo Jacobina Lacombe. Belo Horizonte: Editora Itatiaia, 1990.

GRAHAM. M. Journal of a Residence in Chile. In: HAYWARD, J. (org.). Journal of a Residence in Chile During the Year 1822, and a Voyage from Chile to Brazil in 1823. Charlottesville: University of Virginia Press, 2003.

GRAHAM, M. Journal of a Voyage to Brazil. In: HAYWARD, J.; CABALLERO, S. (orgs.). Maria Graham's Journal of a Voyage to Brazil. South Carolina: Parlor Press, 2010.

KEIGHREN, I.; WITHERS, C. W. J.; BELL, B. (orgs.). Travels into Print: Exploration, Writing, and Publishing with John Murray, 1773-1859. Chicago e Londres: University of Chicago Press, 2015.

LEITE, M. M. (org.). A condição feminina no Rio de Janeiro, século XIX. São Paulo e Brasília: Editora Hucitec, 1984.

LUSTOSA, I. Dom Pedro I: um herói sem nenhum caráter. São Paulo: Companhia das Letras, 2006.

REZZUTTI, P. Domitila. A verdadeira história sobre a marquesa de Santos. Edição digital Kindle. São Paulo: Geração Editorial, 2013.

REZZUTTI, P. Dom Pedro. A história não contada. Edição digital Kindle. São Paulo: Leya Editora, 2015.

REZZUTTI, P. D. Leopoldina. A história não contada: a mulher que arquitetou a Independência do Brasil. Edição digital Kindle. São Paulo: Leya Editora, 2017. 